\title{
THERMODYNAMIC ANALYSIS AND PROCESS SYSTEM COMPARISON OF THE EXHAUST GAS RECIRCULATED, STEAM INJECTED AND HUMIDIFIED MICRO GAS TURBINE
}

\author{
Usman Ali*, Carolina Font Palma, Kevin J Hughes, Derek B Ingham, Lin Ma, Mohamed \\ Pourkashanian
}

\author{
Energy Technology and Innovation Initiative (ETII), Faculty of Engineering, \\ University of Leeds, LS2 9JT, United Kingdom \\ *e-mail address: pmual@leeds.ac.uk
}

\begin{abstract}
Stringent environmental emission regulations and continuing efforts to reduce carbon dioxide $\left(\mathrm{CO}_{2}\right)$ from the energy sector, in the context of global warming, have promoted interest to improve the efficiency of power generation systems whilst reducing emissions. Further, this has led to the development of innovative gas turbine systems which either result in higher electrical efficiency or the reduction of $\mathrm{CO}_{2}$ emissions. Micro gas turbines are one of the secure, economical and environmentally viable options for power and heat generation. Here, a Turbec T100 micro gas turbine (MGT) is simulated using Aspen HYSYS ${ }^{\circledR}$ V8.4 and validated through experimental data. Due to the consistency and robustness of the steady state model developed, it is further extended to three different innovative cycles: (i) an exhaust gas recirculated (EGR) cycle, in which part of the exhaust gas is dried and re-circulated to the MGT inlet; (ii) a steam injected (STIG) cycle, and (iii) a humid air turbine (HAT) cycle. The steam and hot water are generated through the exhaust of the recuperator for the STIG and HAT cycle, respectively. Further, the steam is directly injected into the recuperator for power augmentation, while for the HAT cycle; the compressed air is saturated with water in the humid tower before entering the recuperator. This study evaluates the impact of the EGR ratio, steam to air ratio, and water to air ratio on the performance and efficiency of the system. The comparative potential for each innovative cycle is assessed by thermodynamic properties estimation of process parameters through the models developed to better understand the behavior of each cycle. The thermodynamic assessment indicates that $\mathrm{CO}_{2}$ enrichment occurs for the three innovative cycles. Further, the results indicate that the electrical efficiency increases for the STIG and HAT cycle while it decreases for the EGR cycle. In conclusion, the innovative cycles indicates the possibilities to improve the system performance and efficiency.
\end{abstract}

\author{
NOMENCLATURE \\ CFD Computational fluid dynamics \\ CHP Combined heat and power unit \\ $C_{p} \quad$ molar specific heat capacity at constant pressure, \\ $[\mathrm{J} / \mathrm{mol}-\mathrm{K}]$ \\ $C_{v} \quad$ molar specific heat capacity at constant volume, \\ [J/mol-K] \\ EGR Exhaust gas recirculation \\ G/L Gas/Liquid \\ HAT Humidified air turbine \\ HRSG Heat recovery steam generator \\ IEA International energy agency \\ MGT Micro gas turbine \\ PACT Pilot-scale advanced capture technology \\ STIG Steam injected gas turbine \\ TIT Turbine inlet temperature \\ TOT Turbine outlet temperature \\ UHC Unburned hydrocarbons \\ $\gamma \quad C_{p} / C_{v}$ \\ $\rho \quad$ Mass density, $\left[\mathrm{kg} / \mathrm{m}^{3}\right]$

\section{SUBSCRIPTS} \\ e electrical \\ th thermal
}

\section{BACKGROUND}

According to the IEA [1], the urbanization factor is increasingly leading to higher electricity demand. Currently 1.3 billion people lack access to electricity and there will be 1.7 billion more energy consumers by 2035. Further, more than 2 million people die each year due to indoor and outdoor air pollution [2]. Further, there is growing concern over the climate change across the globe due to the increasing trend in greenhouse gas emissions. Natural gas is a relatively clean fuel, and in the future energy mix, the share of natural gas power plants is expected to grow. Moreover, natural gas power plants are relatively cheap, flexible in operation and control, and emit less $\mathrm{CO}_{2}$ and $\mathrm{NO}_{\mathrm{x}}$ and nearly zero $\mathrm{SO}_{\mathrm{x}}$ compared to other fossil fuels. 
Exhaust gas recirculation (EGR) is an innovative mode of gas turbine operation in which the exhaust gas is split: one part is emitted while the other part is dried before being recirculated to the gas turbine inlet. The benefits of EGR are a decreased flow rate with higher concentration of $\mathrm{CO}_{2}$ in the exhaust gas, which results in a decreased energy penalty when integrated with a $\mathrm{CO}_{2}$ capture system. In spite of the these advantages, the EGR cycle has various technical problems, including the maximum amount of the exhaust gas to be recirculated for maintaining the required level of flame stability, unburned hydrocarbons (UHC) and CO emissions. From the reported literature [3-6], it is recommended that the $\mathrm{O}_{2}$ concentration at the combustor inlet should be higher than $16 \%$ for efficient and stable combustion. It has been observed at $14 \%$ that higher levels of UHC and CO result. Sipocz and Assadi [7] integrated a post combustion capture plant with a 400 MW combined cycle at $40 \%$ EGR with a focus on the methods to reduce the reboiler duty by the steam extraction, and by using an external biomass boiler. Jonshagen et al. [8] developed an IPSE Pro model for the 300 MW GE 109 FB, combined cycle at $40 \%$ EGR and studied the effect of the EGR on the isentropic exponent and gas constant. This results in $8 \%$ $\mathrm{CO}_{2}$ in the outlet and with a focus on the effect on the heat flux diagrams for the HRSG with different alterations for integration with the $\mathrm{CO}_{2}$ capture system. Studies have also included the effect of the EGR on the performance of the post combustion capture plant. A common conclusion may be drawn from the reported literature [9-13] that the EGR may enhance the performance of the gas turbine when integrated with a carbon capture system. Based on a techno-economic analysis, EGR may offer an opportunity to reduce the cost and offer economic benefits for the $\mathrm{CO}_{2}$ capture system $[9,14-16]$. For commercial scale gas turbines, the effect of the EGR on the NGCC power plant is quantified by Canepa et al. [11] and Li et al. [13], while economic evaluation has been performed by Biliyok et al. [9] and Canepa \& Wang [15]. Most of the literature pertains to commercial combined cycle systems with an exhaust gas that already has a higher $\mathrm{CO}_{2}$ content than in the micro gas turbine. For MGT with EGR, the literature reports only $40 \%$ and $50 \%$ EGR ratios [17, 18]. Further, they have compared the EGR and HAT cycle and studied the effect of ambient temperature on the system performance. Cameretti et al. [19, 20] studied the effect of the EGR on the performance of the MGT for different types of fuels and the reduction of $\mathrm{NO}_{\mathrm{x}}$ through CFD modelling of the MGT.

Other novel gas turbine technologies include steam injected gas turbine (STIG) and humidified air turbine (HAT). The waste heat after the expansion of the working fluid can be used to produce steam or to humidify the compressed air; which are then injected into the combustion chamber [21]. It results in an increased mass flow through the expander and hence an increased system efficiency. The different configurations of the STIG and HAT cycles can be found in the literature [22, 23]. Gallo [24] compared the efficiency for HAT, STIG, recuperated and simple cycles and concluded that STIG was better than HAT by varying the specific work. Wang et al. [25] compared the part load performance for the STIG, HAT, water injected with the recuperated and simple cycle. The thermodynamic analysis of the HAT cycle resulted in optimized operating configurations for the machines with higher pressure ratios that ranges from 10-35 [26, 27]. The integration of the HAT cycle with the post combustion capture and the oxy fuel combustion capture for the prototype gas turbine, LM1600PD with a power output of $13.78 \mathrm{MW}$ showed a lower cost in comparison to the natural gas combined cycle [28]. Belokon et al. [29] observed inefficient combustion if the steam to air ratio is higher than $7 \%$ from the experiments performed on the LM5000 combustor. The humidification of the VT40 combustor from 0 to $33 \%$ of water injection reduced $\mathrm{NO}_{\mathrm{x}}$ emissions experimentally [30].

The steam injection in the MGT, along with its thermodynamic analysis, showed an efficiency increase of 5\% [31] while the validation with the experimental data and perturbation analysis indicated an efficiency rise of 2.2\% [32]. The heat exchanger network design for the water injection in the MGT also results in an efficiency increase of 2\% [33]. The HAT cycle configuration for the MGT, along with its thermodynamic assessment, indicates a 4\% efficiency increase [34] and the techno economic assessment of the micro HAT cycle indicated an improved economic performance [35]. An exergy analysis, along with effect of the pressure ratio on the specific power and efficiency, indicated an improved performance for different cycle configurations for water and steam injection at different locations [36]. The spray saturator is designed for the micro HAT cycle by a parametric analysis of the co-, counter- and cross- current saturators [37]. The volume of the spray saturator in [37] is approximately the same as that reported by [34] for the humidifier with packing. The MGT with the HAT, when integrated with an amine capture plant, resulted in higher carbon capture efficiency due to the higher $\mathrm{CO}_{2}$ content [17]. De Paepe et al. [38] have performed the first experimental runs for the MGT with humid air operation.

In spite of the work performed on the commercial scale gas turbines, more work needs to be done to better understand the thermodynamic performance of the three novel cycles, including the EGR, STIG and HAT cycle for the MGT. However, none have compared the MGT for different alterations as performed in this work for the electrical and total efficiency improvements, emissions reduction, the reason and justification for these improvements, and the changing properties of the streams at different levels of the MGT. Due to the limited literature found in this area, an extensive study needs to be performed in this regard. The EGR cycle is relatively new in comparison to the STIG and HAT cycles, especially in the present scenario of targets for reducing $\mathrm{CO}_{2}$ emissions, and its limits needs to be defined as it results in $\mathrm{CO}_{2}$ enhancement with reduced flow rate. The change in the fluid nature, either due to the exhaust gas recycle or the water and steam injection, will affect the stream properties at different positions in the MGT and this result in the varying performance of the MGT. Further, this effect needs to be 
studied in detail for key parameters, such as density, heat capacity, and $\gamma$ as they will disturb the behavior at large due to their contribution in the compressor and the turbine performance equations, and thus sets the focus of the present research. Therefore, this study aims to perform the process system comparison of the aforementioned cycles with MGT. The emphasis has been on analyzing the results generated from process simulation and investigating the thermodynamic properties of the system as a whole and the streams at different locations in the system to assess the performance of the innovative cycles.

In this paper, the Turbec T100 micro gas turbine is studied as the base case. The MGT is located at the UKCCS research center, Pilot-scale Advanced Capture Technology (PACT) facility in Sheffield, UK [39]. The MGT is modelled and simulated using Aspen HYSYS ${ }^{\circledR}$ V8.4 and validated through the experimental data. The steady state model developed is further extended to three different innovative cycles, i.e. (i) EGR cycle, (ii) STIG cycle, and (iii) HAT cycle. This paper focuses on a systematic comparative analysis of the MGT, EGR, STIG, and HAT cycles in terms of performance and emissions. This study evaluates the MGT cycle against the impacts of the EGR ratio, steam to air ratio, and water to air ratio, respectively, on the performance and efficiency of the system. The availability of the thermal output is also quantified for each cycle configuration. The enrichment of $\mathrm{CO}_{2}$ in the flue gas for each novel cycle is quantified and its effect on the $\mathrm{CO}_{2}$ capture plant is implicitly defined. However, the details of the integration with the $\mathrm{CO}_{2}$ capture plant are beyond the scope of this research. The thermodynamic properties of the fluid at different locations of the MGT, for each alteration are assessed in order to determine the comparative impact on the performance.

\section{PROCESS CONFIGURATIONS}

This section deals with the configuration of the base case MGT cycle, EGR, STIG, and HAT cycle. The layout of each cycle, along with a brief description of the system and its modelling methodology, are presented. The behavior and limitations of each cycle are also discussed.

\subsection{MGT CYCLE}

The Turbec T100 MGT is a combined heat and power unit capable of producing $100 \mathrm{~kW}_{\mathrm{e}}$ power with $\sim 150 \mathrm{~kW}_{\mathrm{th}}$ [40]. It comprises a centrifugal compressor, radial turbine and high speed generator, and all are mounted on the same shaft with a pressure ratio of 4.5:1. The combustor is a lean pre-mix emission type with low $\mathrm{NO}_{\mathrm{x}}, \mathrm{CO}$ and UHC. There are also two heat exchangers, one is the recuperator used to preheat the compressed air before injecting it to the combustor using the hot exhaust gases from the turbine, thus increasing the efficiency of the turbine. The other is a gas-water heat exchanger, which generates thermal power by extracting heat from the outlet of the gas side of the recuperator. The configuration of the MGT components is shown in Figure 1.

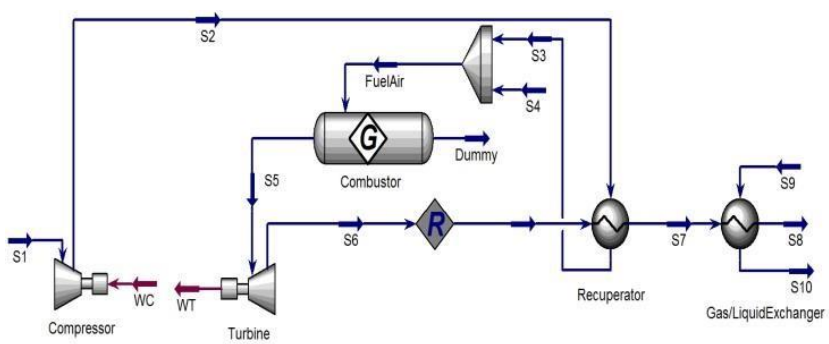

Figure 1: Schematic of the MGT model developed.

The MGT with the recuperator and gas-water heat exchanger is designed for CHP generation. The MGT with CHP mode is modelled and simulated using Aspen HYSYS ${ }^{\circledR}$ V8.4. The property package used for the thermodynamic property estimation is the Peng Robinson equation of state. Chemical equilibrium in the combustor is estimated by the minimization of the total Gibbs free energy. The major components of the model include the compressor, turbine, combustor, two heat exchangers, mixer and splitter. The model is capable of estimating minor species, including carbon monoxide, sulfur dioxide, as well as nitrogen based species, such as nitrogen dioxide, nitrous oxide and nitric oxide. The base case model was developed at ISO conditions [41] for $100 \mathrm{~kW}_{\mathrm{e}}$ with the constraint of turbine inlet temperature (TIT) and turbine outlet temperature (TOT) within the limits of $950^{\circ} \mathrm{C}$ and $650^{\circ} \mathrm{C}$, respectively. The composition of the natural gas used in the model is listed in Table 1. The developed steady state base case model is extended to perform simulations for the different power outputs (50-100 $\mathrm{kW}_{\mathrm{e}}$ ) to represent various operational scenarios. The turbine outlet temperature and flue gas composition were measured experimentally at the PACT Core facility. After evaluating against experimental data, the resulting model is sufficiently robust to analyze other novel MGT cycles.

Table 1: Natural gas composition.

\begin{tabular}{ll}
\hline Component & Mole fraction \\
\hline $\mathrm{CH}_{4}$ & 0.906 \\
$\mathrm{C}_{2} \mathrm{H}_{6}$ & 0.051 \\
$\mathrm{C}_{3} \mathrm{H}_{8}$ & 0.013 \\
$\mathrm{i}-\mathrm{C}_{4} \mathrm{H}_{10}$ & 0.002 \\
$n-\mathrm{C}_{4} \mathrm{H}_{10}$ & 0.002 \\
$\mathrm{~N}_{2}$ & 0.011 \\
$\mathrm{CO}_{2}$ & 0.014 \\
\hline
\end{tabular}

\subsection{EGR CYCLE}

Due to the lean pre-mix emission type combustor, the outlet exhaust composition is much leaner than in large commercial gas turbines. The composition of the $\mathrm{CO}_{2}$ is only 1.6 to $1.8 \mathrm{~mol} \%$ in the MGT, while the $\mathrm{CO}_{2}$ concentration from an industrial or commercial scale gas turbine is in the range of 3.8 to $4.4 \mathrm{~mol} \%$ $[11-13,16]$. Therefore, the MGT needs to be $\mathrm{CO}_{2}$ enhanced 
before integrating it with the carbon capture system. One option is the EGR in which the part of the exhaust gas is split, dried, and recirculated back to the MGT inlet. The default configuration of the MGT remains the same with the additional equipment, including a splitter for splitting the exhaust gas into two streams, a condenser for cooling and drying of the recycle stream to the required level, and a booster fan to recirculate the recycle stream to the compressor inlet. The EGR cycle model developed is shown in Figure 2, with the upper dotted rectangle showing the default MGT, and the lower rectangle with dashed lines representing the recycle loop. The default MGT is still in the CHP mode while the recycle loop directs a portion of the exhaust gas back to the compressor inlet with the required properties.

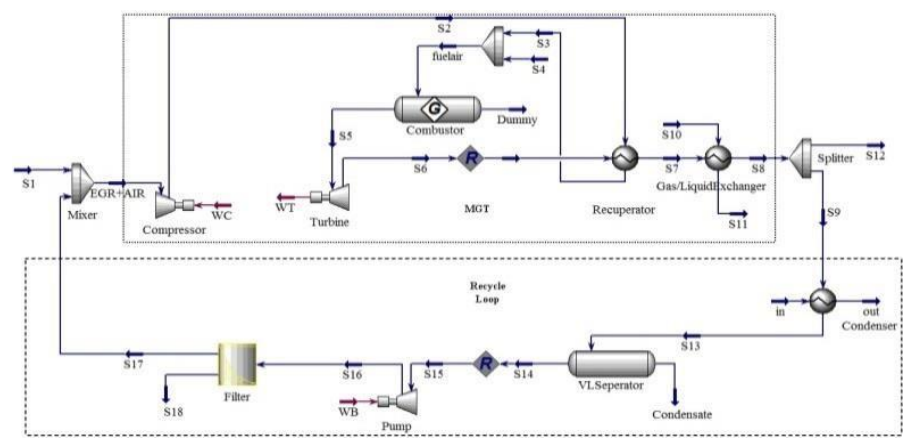

Figure 2: Flow sheet of the EGR cycle model developed.

The amount of the exhaust gas recirculated can be defined by the following equation:

$$
\text { EGR ratio }=\frac{\text { Volume flow of recirculated exhaust gas }}{\text { Volume flow of exhaust gas }}
$$

The steady state base case model of the MGT is extended to include the EGR mode. The EGR ratio is varied to evaluate the $\mathrm{CO}_{2}$ enrichment with a decreasing trend in the $\mathrm{O}_{2}$ concentration in the flue gas and affecting the performance of the system.

\subsection{STIG CYCLE}

An option to increase the efficiency of the system is the injection of steam into the MGT. The steam can be injected into the MGT at three different locations, the compressor inlet, compressor outlet/recuperator inlet, or recuperator outlet/combustor inlet. Each location has its own technical problems and benefits and further details can be found in the literature [42]. In this work, the water or steam is injected at the recuperator inlet. The steam can be auto generated by utilizing the waste heat available after the recuperator. In order to inject the steam smoothly, the injection pressure of the steam should be higher than the live stream pressure at the injection point. The steam is generated at the saturation pressure corresponding to the saturation temperature of $150^{\circ} \mathrm{C}$. The steady state base case model was altered in such a way to study the degradation of the thermal power due to the addition of the steam generator for auto steam generation. The three heat exchangers, namely recuperator, steam generator and gas-water heat exchanger, are arranged in series as shown in Figure 3 in order to extract as much heat as possible from the exhaust of the turbine whilst keeping the pinch point of each heat exchanger. The NBS Steam property package was chosen for the water loop in the STIG cycle and it gives better results in comparison to the ASME 1967 steam property package.

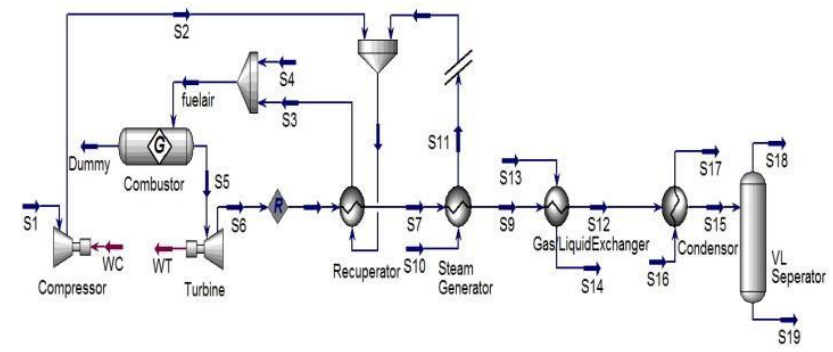

Figure 3: Schematic of the STIG cycle model developed.

\subsection{HAT CYCLE}

The pinch point limitation of the steam injection can be avoided by altering the MGT to a HAT cycle. Further, the need for steam generation can be avoided by the implementation of the humidification system, so that the exhaust gas temperatures closely match, in a reversible manner. In the humidification tower, the water evaporates below the boiling point corresponding to the partial pressure of the water in the mixture at the prevailing total pressure in the tower. The pinch point limitation of the boiler, plus the problem of not utilizing the low grade heat to evaporate the water limits the steam injection process; in contrast, in the humidified tower, the air is saturated with water so that the water stream evaporates across the height of the tower at the different saturation temperatures prevailing at the corresponding pressure; the process of humidification is nonisothermal in comparison to the isothermal boiling. In a HAT cycle, the compressed air passes through the humidification tower and the saturated air from the top of the tower passes through the recuperator and then to the combustor. The water entering the humidification tower is preheated close to the saturation temperature, through an economizer installed after the recuperator in series. In the humidification tower, air and water are in contact counter currently and thus results in an increase in the evaporation temperature as the air moves up the tower. The major components added to the MGT for the HAT cycle includes: the humidification tower for air humidification, the heat exchanger as an economizer for the water heating, the condenser to remove the water from the exhaust gas, two pumps (one for the condensate water recirculation back to the economizer, while second is for the recirculation of the water from the bottom of the humidification tower back to the economizer), the splitters, and the mixers. The splitter after the compressor is for the bypass of the humidification tower when the MGT is to be operated dry or on partial HAT. The HAT cycle is schematically shown in Figure 4. The water recirculation reduces the water make-up; however, due to water quality issues, the regular make-ups are necessary. 


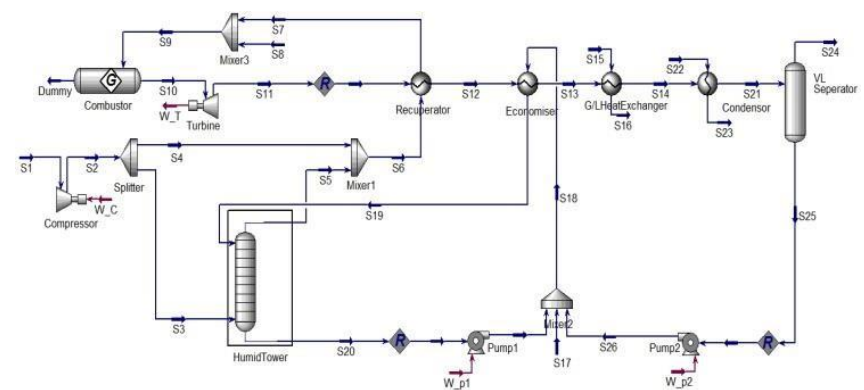

Figure 4: Schematic of the HAT cycle model developed.

\section{RESULTS AND DISCUSSIONS}

In this section, the modeling and simulation of each case of the MGT, including the base case MGT, EGR, STIG and HAT are presented in detail along with their comparative performance. Each model is developed for a constant electrical power output of $100 \mathrm{~kW}_{\mathrm{e}}$ at ISO conditions and maintaining the TOT constant at the same value as in the base case.

\subsection{MGT BASE CASE}

The MGT is controlled by the rotational speed it adopts itself by controlling the natural gas flow rate for a constant TOT of $645^{\circ} \mathrm{C}$. The base case model is developed at ISO conditions with an electric power output of $100 \mathrm{~kW}_{\mathrm{e}}$ and this result in a thermal output of $153.3 \mathrm{~kW}_{\text {th }}$. The base case model is in good agreement with the reference data [40], and the details are listed in Table 2. The model is evaluated against the available set of experimental data to check the flexibility of the model. The electrical power output is varied from 50 to $80 \mathrm{~kW}_{\mathrm{e}}$ to represent different operational modes and the simulations are performed for each case and compared with the mean values of some experimental data points. Further, the measured and simulated results are consistent and agree well. The measured and simulated $\mathrm{CO}_{2}$ and $\mathrm{O}_{2}$ molar gas composition in the flue gas at different electric power output are shown in Figure 5 (a) with mean percent absolute deviations of 7.4 and $2.0 \%$, respectively.
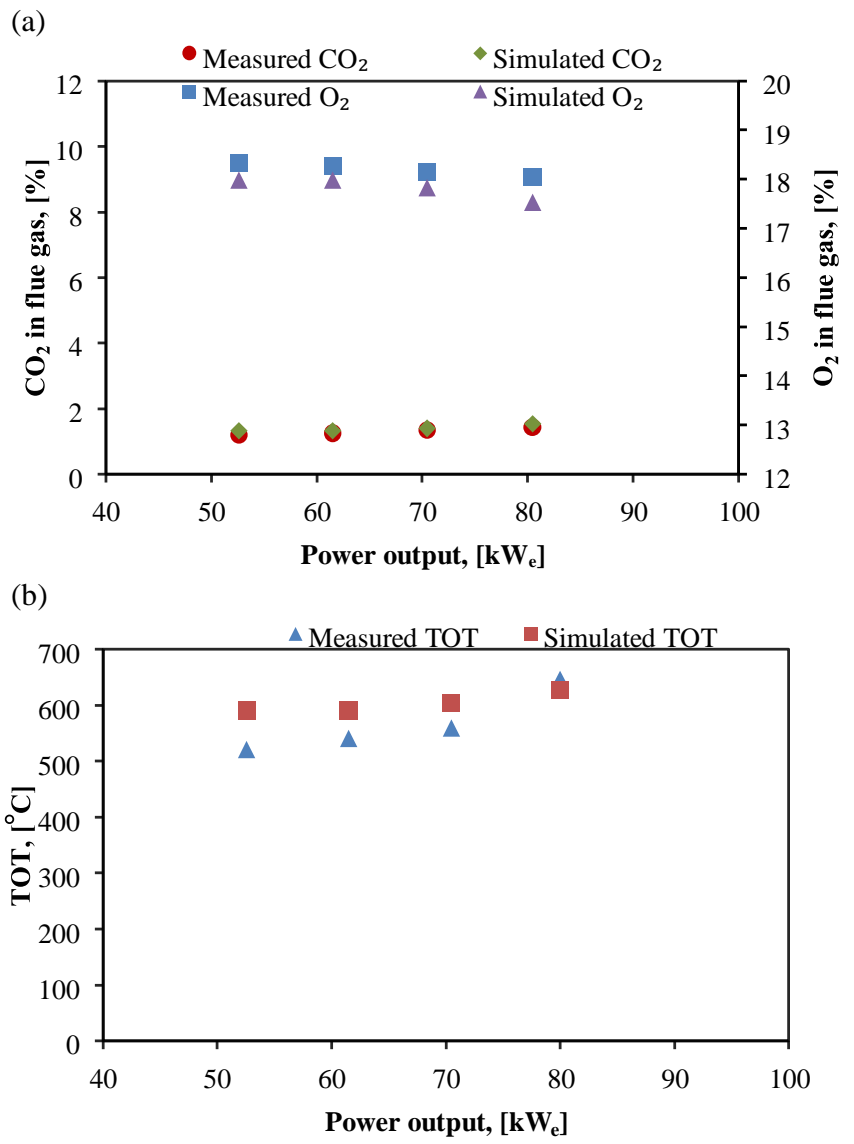

Figure 5: Measured versus simulated data (a) $\mathrm{CO}_{2}$ and $\mathrm{O}_{2}$ molar composition in flue gas; and (b) TOT.

Table 2: Performance of different cycles at ISO condition.

\begin{tabular}{|c|c|c|c|c|}
\hline Parameter & MGT cycle & EGR cycle & STIG cycle & HAT cycle \\
\hline Electrical power output $\left(\mathrm{kW}_{\mathrm{e}}\right)$ & 100 & 95.8 & 100 & 100 \\
\hline Thermal output $\left(\mathrm{kW}_{\mathrm{th}}\right)$ & 153.3 & 179 & 96.6 & 43.7 \\
\hline Recuperator duty (kW) & 267 & 274.6 & 257 & 336 \\
\hline Electrical efficiency (\%) & 32.1 & 29 & 34.1 & 34 \\
\hline Net total efficiency $(\%)$ & 81.2 & 83.3 & 67.1 & 48.9 \\
\hline Pressure ratio & 4.5 & 4.5 & 4.5 & 4.5 \\
\hline Turbine inlet temperature $\left({ }^{\circ} \mathrm{C}\right)$ & 945 & 950 & 942 & 857 \\
\hline Turbine outlet temperature $\left({ }^{\circ} \mathrm{C}\right)$ & 644 & 650 & 645 & 580 \\
\hline $\mathrm{CO}_{2}$ molar composition in flue gas $(\%)$ & 1.6 & 3.7 & 1.8 & 1.7 \\
\hline $\mathrm{O}_{2}$ molar composition in flue gas $(\%)$ & 17.3 & 13.4 & 17.7 & 17.6 \\
\hline $\mathrm{NO}_{\mathrm{x}}$ molar composition in flue gas (ppm) & 2.3 & 2.0 & 2.1 & 1.0 \\
\hline Flue gas flow rate $(\mathrm{kg} / \mathrm{s})$ & 0.67 & 0.31 & 0.58 & 0.62 \\
\hline EGR ratio $(\%)$ & - & 55 & - & - \\
\hline Steam/water injected $(\mathrm{g} / \mathrm{s})$ & - & - & 17.7 & 40 \\
\hline Condensation temperature $\left({ }^{\circ} \mathrm{C}\right)$ & - & 40 & 15 & 15 \\
\hline $\mathrm{G} / \mathrm{L}$ heat exchanger water side range $\left({ }^{\circ} \mathrm{C}\right)$ & 20 & 20 & 20 & 20 \\
\hline
\end{tabular}


While the measured and simulated TOT is illustrated in Figure 5 (b) with a mean percent absolute deviation of $8.5 \%$. It is necessary to mention that this set of experimental data was recorded over a short period of cold start-up, and this is the reason for the varying TOT.

The MGT is being modified to include more instrumentation at various locations for the temperature, pressure and flow rate measurements. It is expected that in the near future, more extensive experimental data will be available. The resulting validated model is robust enough to extend it to different alternatives of the MGT.

\subsection{IMPACT OF EGR RATIO}

From the aforementioned MGT base case, it is clear that the flue gas from the MGT is very lean with respect to the $\mathrm{CO}_{2}$ molar composition, and will increase the penalty when it is integrated with the carbon capture system. Because of this, the EGR cycle is implemented and its performance is evaluated by varying the EGR ratio from 0 to $80 \%$. It is observed that with an increase in the EGR ratio, the $\mathrm{CO}_{2}$ molar composition increases while the $\mathrm{O}_{2}$ molar composition decreases as depicted in Figure 6 (a). This can result in $\mathrm{O}_{2}$ starvation at the combustor inlet as the EGR ratio increases beyond some specific point. The limit of $16 \mathrm{~mol} \% \mathrm{O}_{2}$ at the combustor inlet for efficient combustion should be maintained based on the recommendations from the literature [4-6]. Below this limit, the combustion efficiency, stability, and kinetics will be negatively affected by the higher UHC and $\mathrm{CO}$ emissions [4]. Based on this limiting $\mathrm{O}_{2}$ value, Figure 6(b) shows that the EGR ratio at or below $55 \%$ is recommended. The results of the EGR cycle at 55\% EGR ratio are presented in Table 2. The $\mathrm{CO}_{2}$ composition in the flue gas is increased by a factor of about 2.3 compared to the MGT with no recycle and this increase is approximately the same as that reported in the literature [8, 9, 14-16] for the commercial scale gas turbine systems with EGR. The efficiency for the EGR cycle is decreased to about $29 \%$ from $32.1 \%$ of the base case MGT cycle. This decrease is due to the blower power in recirculating the exhaust gas from the condenser pressure back to the compressor inlet. The effect of the EGR ratio on the decrease in the electrical efficiency is shown in Figure 6 (c). The flue gas flow rate of the EGR cycle decreases more than $50 \%$ of the base case MGT cycle which results in a better performance for the carbon capture plant. This, along with enhanced $\mathrm{CO}_{2}$ concentration, will benefit the economics of the system when integrated with a smaller-size carbon capture system.

The enhanced thermal output of the EGR cycle in comparison with the MGT cycle results in an improved performance of the bottom Rankine cycle in commercial gas turbines.

\subsection{IMPACT OF STEAM INJECTION}

The auto generated saturated steam at a temperature of $150^{\circ} \mathrm{C}$ is injected into the MGT at the compressor outlet/recuperator air side inlet and thus results in an increased electrical efficiency. For more details of the STIG model developed, refer to Section 2.3.

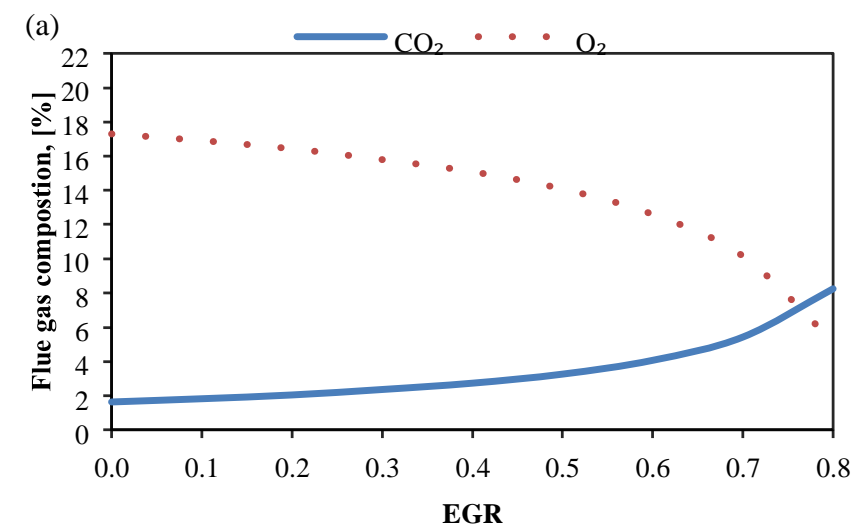

(b)

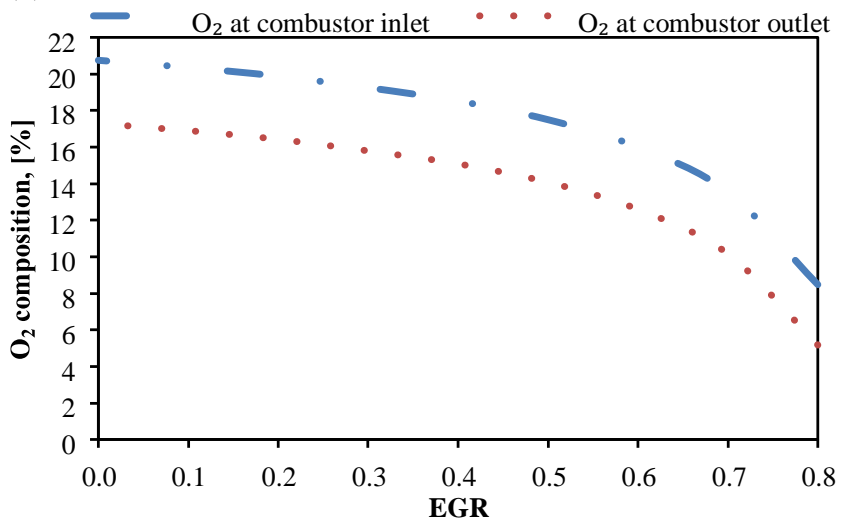

(c)

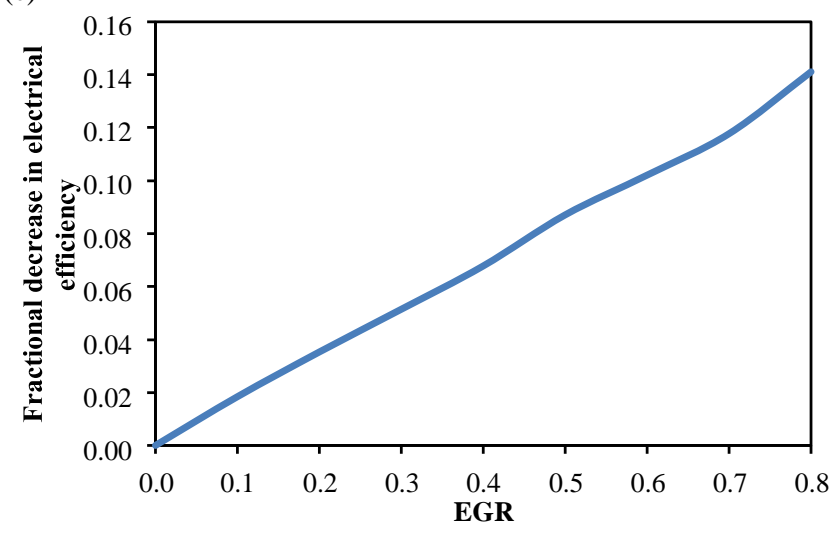

Figure 6: Impact of EGR ratio (a) $\mathrm{CO}_{2}$ and $\mathrm{O}_{2}$ molar composition in flue gas; (b) $\mathrm{O}_{2}$ molar composition at the combustor inlet and outlet; and (c) impact of EGR on the electrical efficiency.

The fractional increase in the electrical efficiency with the increase in the steam to air ratio is shown in Figure 7, and the 
performance of the steam injected MGT is given in Table 2, keeping the amount of the steam injected within the range reported in the literature [31-33] for the MGT. The increase in the electrical efficiency is due to the increased mass flow through the turbine section. Further, the steam injection leads to the increase electrical efficiency of $2 \%$ absolute, the same as reported by [32]. The condenser installed at the exit of the $\mathrm{G} / \mathrm{L}$ heat exchanger results in the enrichment of the $\mathrm{CO}_{2}$ in the flue gas, which will be useful for the carbon capture plant as the increased partial pressure of the $\mathrm{CO}_{2}$ aids in its capture. The $\mathrm{CO}_{2}$ in the flue gas increases to $1.8 \mathrm{~mol} \%$ for the STIG cycle from $1.6 \mathrm{~mol} \%$ with no steam injection. The condenser also reduces the make-up water demand; however, due to water quality issues, the condensate is not recirculated in the model developed. The steam injection results in the degradation of the thermal output when steam is auto generated from the MGT. It may be concluded that the thermal mode needs to be disabled for the auto generation of the steam from the MGT due to the higher exergy destruction in the steam generator. The thermal output decreased by $37 \%$ from the base case MGT and hence the net total efficiency also decreased. For commercial gas turbine systems, steam injection may lead to the omission of the bottom Rankine cycle. However, steam injection may lead to combustion problems in terms of flame instability with higher UHC and $\mathrm{CO}$ emissions, which may need combustor modifications to mitigate this effect. For the MGT, as the steam injected is much less than the reported by [29], it will not result in severe combustion instability in the MGT.

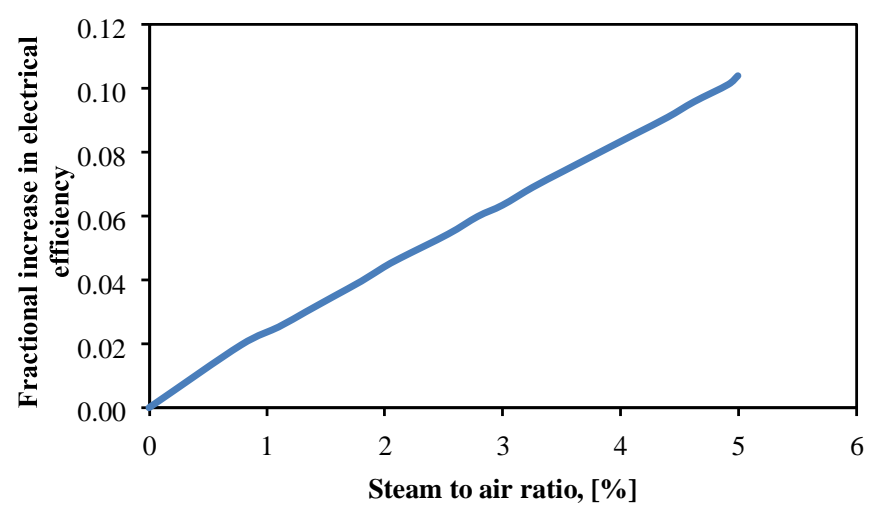

Figure 7: Impact of steam injection on the electrical efficiency.

\subsection{IMPACT OF HAT}

The MGT cycle is altered to check the behavior of the system when humidified air is used for the combustion and further expansion through the turbine. The details of the HAT cycle can be found in Section 2.4. The compressed air is passed through the humidification tower with the dimensions as in [34, 37] and the humidified air is injected once it is saturated at the outlet. If any carryover of the droplets occurs through the humidification tower, these can be evaporated by heating the air through the recuperator before the combustion section. The HAT cycle increases the electrical efficiency similarly to the STIG cycle. The fractional increase in the electrical efficiency with the increase after the water injection to air is shown in Figure 8 and the performance of the HAT cycle is listed in Table 2. The amount of water injected is limited to, as reported in the literature [34] for the MGT. The HAT cycle increases the electrical efficiency by approximately $2 \%$ absolute, being approximately the same as reported by $[33,34]$. The HAT cycle decreases by approximately $70 \%$ the thermal output and the net total efficiency is limited to $48.9 \%$ in comparison to $81.2 \%$ for the base case MGT. Part of the thermal duty is consumed by the economizer for the preheating of the water before injecting it into the humidification tower. Due to disabling of the thermal mode, the HAT cycle will also omit the bottom Rankine cycle in a commercial gas turbine system similar to the STIG cycle. The condenser will result in a negative make-up due to the extra water condensed then injected due to the higher $\mathrm{H} / \mathrm{C}$ ratio of the natural gas. The extra water comes from the natural gas combustion due to the higher $\mathrm{H} / \mathrm{C}$ ratio. The condenser also contributes to the enrichment of $\mathrm{CO}_{2}$ from 1.6 to $1.7 \mathrm{~mol} \%$ in the flue gas. The injected water may cause combustion instability and flame fluctuation, which can be implied by the decrease of the TIT and TOT. $\mathrm{NO}_{\mathrm{x}}$ emissions are lower than the environmentally set standard for emissions; for each of the novel micro gas turbines studied and decreased for each alteration in comparison to the base case. $\mathrm{NO}_{\mathrm{x}}$ emissions are lowest for the HAT cycle in comparison to the other alterations, also reported by [30]. Hence, the HAT cycle needs combustor modifications to cope with the change of stream properties.

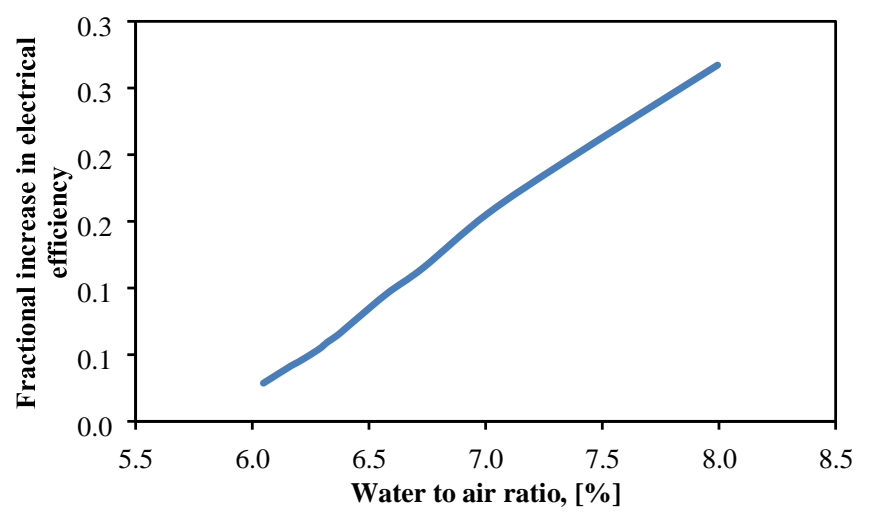

Figure 8: Impact of HAT on the electrical efficiency.

\subsection{COMPARATIVE POTENTIAL}

The change in the thermodynamic properties of the fluid at different locations in all the aforementioned cycles is listed in Table 3. The change in the thermodynamic properties is due to the change in the composition of the streams due to either the recycle or injection of water or steam. The mass density of the fluid follows the trend of HAT $>M G T>S T I G>E G R$ at the recuperator inlet and turbine inlet, while at the turbine outlet the 
trend is HAT $>$ MGT $>$ EGR $>$ STIG. The heat capacity of the EGR cycle at the recuperator inlet, turbine inlet and turbine outlet is higher than in the other three cycles. While at the recuperator inlet the trend of STIG>MGT>HAT is observed. On the other hand, at the turbine inlet and outlet, the heat capacity varies in the order of STIG>HAT>MGT. Similar trends can be traced for the ratio of molar specific heat at constant pressure to that at constant volume $(\gamma)$ value. Due to the increased density, the heat duty of the recuperator is higher for the HAT cycle. However, for the EGR cycle the increased heat duty of the recuperator and $\mathrm{G} / \mathrm{L}$ heat exchanger is due to the increased heat capacity. It can be concluded that the performance of the MGT with its different alterations can be judged by understanding the thermodynamic properties of the fluid at different locations.

Table 3: Thermodynamic properties of the fluid at different location in different alterations of the MGT.

\begin{tabular}{|c|c|c|c|}
\hline & $\begin{array}{l}\text { Mass } \\
\text { density, }[\rho]\end{array}$ & $\begin{array}{l}\text { Heat } \\
\text { Capacity, } \\
{\left[C_{p}\right]}\end{array}$ & $\gamma=C_{p} / C_{v}$ \\
\hline Units & $\mathrm{kg} / \mathrm{m}^{3}$ & $\begin{array}{c}\mathrm{kJ} / \mathrm{mol} \mathrm{K} \\
\text { MGT cycle }\end{array}$ & - \\
\hline Compressor inlet & 1.21 & 29.1 & 1.403 \\
\hline Recuperator inlet & 3.18 & 30.4 & 1.381 \\
\hline Turbine inlet & 1.27 & 34.6 & 1.317 \\
\hline Turbine outlet & 0.376 & $\begin{array}{l}33.2 \\
\text { EGR cycle }\end{array}$ & 1.335 \\
\hline Compressor inlet & 1.15 & 29.5 & 1.397 \\
\hline Recuperator inlet & 3.05 & 30.9 & 1.373 \\
\hline Turbine inlet & 1.26 & 35.2 & 1.310 \\
\hline Turbine outlet & 0.372 & $\begin{array}{c}33.7 \\
\text { STIG cycle }\end{array}$ & 1.328 \\
\hline Compressor inlet & 1.21 & 29.1 & 1.403 \\
\hline Recuperator inlet & 3.15 & 30.6 & 1.378 \\
\hline Turbine inlet & 1.25 & 35.0 & 1.312 \\
\hline Turbine outlet & 0.369 & $\begin{array}{l}33.5 \\
\text { HAT cycle }\end{array}$ & 1.330 \\
\hline Compressor inlet & 1.21 & 29.1 & 1.403 \\
\hline Recuperator inlet & 4.31 & 30.1 & 1.398 \\
\hline Turbine inlet & 1.33 & 35.0 & 1.312 \\
\hline Turbine outlet & 0.390 & 33.4 & 1.331 \\
\hline
\end{tabular}

Despite the technical challenges for the each cycle presented, combustion instability is the issue of concern because it may result in flame instability along with higher UHC and CO emissions due to the change in the fluid properties. Modifications in the combustor may therefore be required for these three novel cycles. The injection of steam and water in the STIG and HAT cycles, respectively, may also result in an imbalance on the shaft as the mass flow of the fluid is different, which is expanding through the turbine section, in comparison to the fluid which is compressed.

\section{CONCLUSIONS}

The thermodynamic performance of three novel cycles, namely EGR, STIG and HAT cycles are compared with the base case MGT cycle. The thermodynamic analysis and process simulation provide detailed information on the performance of the novel cycles demonstrate the MGT applicability and flexibility.

The base case model of the MGT validated with experimental data can be reasonably used to evaluate the performance of the different novel cycles. The thermodynamic assessment and process simulation showed that the $\mathrm{CO}_{2}$ enrichment varies from $1.6 \mathrm{~mol} \%$ in the base case MGT cycle to 3.7, 1.8 and $1.7 \mathrm{~mol} \%$ in the EGR, STIG and HAT cycles, respectively. The increased $\mathrm{CO}_{2}$ content in the flue gas of all the novel cycles show a potential advantage when integrated with a $\mathrm{CO}_{2}$ capture plant. Moreover, for the EGR cycle, the flue gas flow rate could be decreased by $50 \%$, which will require a smaller $\mathrm{CO}_{2}$ capture plant.

The results show that the electrical efficiency increases by $6 \%$ for the HAT and STIG cycles and decreases by $9 \%$ for the EGR cycle, from the base case MGT cycle with an electrical efficiency of $32.1 \%$. Due to the higher total efficiency, the EGR cycle is superior to the other two cycles, especially for the integration with a $\mathrm{CO}_{2}$ capture system as a result of $\mathrm{CO}_{2}$ enrichment. However, at a distributive level of power generation, where the sole purpose is to have the highest electrical power output, the STIG and HAT cycles will be the preferred choices due to the higher electrical efficiency. Therefore, in spite of the technical challenges, the innovative cycles show the potential to improve the performance in terms of either efficiency or $\mathrm{CO}_{2}$ capture readiness due to $\mathrm{CO}_{2}$ enrichment. There is trade-off between $\mathrm{CO}_{2}$ enhancement and increase in electrical efficiency and the choice of MGT cycle should depend on the adopted criteria.

\section{ACKNOWLEDGMENTS}

The authors wish to thank Dr Karen N Finney and Thom Best for proving the experimental results for validation. Usman Ali acknowledges the grant provided by the University of Engineering and Technology, Lahore Pakistan and the partial support by the ETII, University of Leeds, UK, in support of this research.

\section{REFERENCES}

[1] IEA. (2012). World Energy Outlook 2012: OECD Publishing.

[2] WHO. (2011). Tackling the Global Clean Air Challenge. World Health Organization, Geneva.

[3] Bolland, O., \& Mathieu, P. (1998). Comparison of two $\mathrm{CO}_{2}$ removal options in combined cycle power plants. Energy Conversion and Management, 39(16), 16531663. 
[4] Ditaranto, M., Hals, J., \& Bjørge, T. (2009). Investigation on the in-flame NO reburning in turbine exhaust gas. Proceedings of the Combustion Institute, 32(2), 2659-2666.

[5] ElKady, A. M., Ursin, T. P., Lynghjem, A., Evulet, A., \& Brand, A. (2009). Application of exhaust gas recirculation in a DLN F-class combustion system for postcombustion carbon capture. Journal of Engineering for Gas Turbines and Power, 131(3), 034505.

[6] Evulet, A. T., ELKady, A. M., Branda, A. R., \& Chinn, D. (2009). On the Performance and Operability of GE's Dry Low $\mathrm{NO}_{\mathrm{x}}$ Combustors utilizing Exhaust Gas Recirculation for PostCombustion Carbon Capture. Energy Procedia, 1(1), 3809-3816.

[7] SipÃḳcz, N., \& Assadi, M. (2010). Combined cycles with $\mathrm{CO}_{2}$ capture: two alternatives for system integration. Journal of Engineering for Gas Turbines and Power, 132(6), 061701.

[8] Jonshagen, K., Sipöcz, N., \& Genrup, M. (2010). Optimal Combined cycle for $\mathrm{CO}_{2}$ capture with EGR.

Paper presented at the ASME Turbo Expo 2010: Power for Land, Sea, and Air.

[9] Biliyok, C., Canepa, R., Wang, M., \& Yeung, H. (2013). Techno-Economic Analysis of a Natural Gas Combined Cycle Power Plant with $\mathrm{CO}_{2}$ Capture. In K. Andrzej \& T. Ilkka (Eds.), Computer Aided Chemical Engineering (Vol. 32, pp. 187-192): Elsevier.

[10] Botero, C., Finkenrath, M., Bartlett, M., Chu, R., Choi, G., \& Chinn, D. (2009). Redesign, Optimization, and Economic Evaluation of a Natural Gas Combined Cycle with the Best Integrated Technology $\mathrm{CO}_{2}$ Capture. Energy Procedia, 1(1), 3835-3842.

[11] Canepa, R., Wang, M., Biliyok, C., \& Satta, A. (2013). Thermodynamic analysis of combined cycle gas turbine power plant with post-combustion $\mathrm{CO}_{2}$ capture and exhaust gas recirculation. Proceedings of the Institution of Mechanical Engineers, Part E: Journal of Process Mechanical Engineering, 227(2), 89-105.

[12] Li, H., Ditaranto, M., \& Berstad, D. (2011). Technologies for increasing $\mathrm{CO}_{2}$ concentration in exhaust gas from natural gas-fired power production with post-combustion, amine-based $\mathrm{CO}_{2}$ capture. Energy, 36(2), 1124-1133.

[13] Li, H., Haugen, G., Ditaranto, M., Berstad, D., \& Jordal, K. (2011). Impacts of exhaust gas recirculation (EGR) on the natural gas combined cycle integrated with chemical absorption $\mathrm{CO}_{2}$ capture technology. Energy Procedia, 4, 1411-1418.

[14] Biliyok, C., \& Yeung, H. (2013). Evaluation of natural gas combined cycle power plant for post-combustion $\mathrm{CO}_{2}$ capture integration. International Journal of Greenhouse Gas Control, 19(0), 396-405.

[15] Canepa, R., \& Wang, M. (2014). Techno-economic analysis of a $\mathrm{CO}_{2}$ capture plant integrated with a commercial scale combined cycle gas turbine (CCGT) power plant. Applied Thermal Engineering (0).

[16] Sipöcz, N., \& Tobiesen, F. A. (2012). Natural gas combined cycle power plants with $\mathrm{CO}_{2}$ capture Opportunities to reduce cost. International Journal of Greenhouse Gas Control, 7(0), 98-106.

[17] Majoumerd, M. M., Somehsaraei, H. N., Assadi, M., \& Breuhaus, P. (2014). Micro gas turbine configurations with carbon capture - Performance assessment using a validated thermodynamic model. Applied Thermal Engineering.

[18] Nikpey, H., Majoumerd, M. M., Assadi, M., \& Breuhaus, P. (2014). Thermodynamic analysis of innovative micro gas turbine cycles. Paper presented at the ASME Turbo Expo 2014: Germany.

[19] Cameretti, M. C., Piazzesi, R., Reale, F., \& Tuccillo, R. (2009). Combustion simulation of an exhaust gas recirculation operated micro-gas turbine. Journal of engineering for gas turbines and power, 131(5).

[20] Cameretti, M. C., Tuccillo, R., \& Piazzesi, R. (2013). Study of an EGR Equipped Micro Gas Turbine supplied with bio-fuels. Applied Thermal Engineering.

[21] Poullikkas, A. (2005). An overview of current and future sustainable gas turbine technologies. Renewable and Sustainable Energy Reviews, 9(5), 409-443.

[22] Heppenstall, T. (1998). Advanced gas turbine cycles for power generation: a critical review. Applied Thermal Engineering, 18(9), 837-846.

[23] Jonsson, M., \& Yan, J. (2005). Humidified gas turbines - a review of proposed and implemented cycles. Energy, 30(7), 1013-1078.

[24] Gallo, W. L. (1997). A comparison between the HAT cycle and other gas-turbine based cycles: efficiency, specific power and water consumption. Energy Conversion and Management, 38(15), 1595-1604.

[25] Wang, B., Zhang, S., \& Xiao, Y. (2007). Steady-state off-design performance of humid air turbine cycle. ASME Paper No. GT2007-27350.

[26] Nyberg, B., \& Thern, M. (2012). Thermodynamic studies of a HAT cycle and its components. Applied Energy, 89(1), 315-321.

[27] Xiao, Y., Cai, R., \& Lin, R. (1997). Modeling HAT cycle and thermodynamic evaluation. Energy conversion and Management, 38(15), 1605-1612.

[28] Hu, Y., Li, H., \& Yan, J. (2012). Techno-economic evaluation of the evaporative gas turbine cycle with different $\mathrm{CO}_{2}$ capture options. Applied Energy, 89(1), 303-314.

[29] Belokon, A. A., Khritov, K. M., Klyachko, L. A., Tschepin, S. A., Zakharov, V. M., \& Opdyke, G. (2002). Prediction of Combustion Efficiency and $N O_{x}$ Levels for Diffusion Flame Combustors in HAT Cycles. 
Paper presented at the ASME Turbo Expo 2002: Power for Land, Sea, and Air.

[30] Hermann, F., Klingmann, J., \& Gabrielsson, R. (2003). Computational and experimental investigation of emissions in a highly humidified premixed flame. Paper presented at the ASME Turbo Expo 2003, collocated with the 2003 International Joint Power Generation Conference.

[31] Delattin, F., Bram, S., Knoops, S., \& De Ruyck, J. (2008). Effects of steam injection on microturbine efficiency and performance. Energy, 33(2), 241-247.

[32] De Paepe, W., Delattin, F., Bram, S., \& De Ruyck, J. (2012). Steam injection experiments in a microturbine - A thermodynamic performance analysis. Applied Energy, 97, 569-576.

[33] De Paepe, W., Delattin, F., Bram, S., \& De Ruyck, J. (2013). Water injection in a micro gas turbineAssessment of the performance using a black box method. Applied Energy, 112, 1291-1302.

[34] Parente, J., Traverso, A., \& Massardo, A. (2003). Micro Humid Air Cycle: Part A-Thermodynamic and Technical Aspects.

[35] Parente, J., Traverso, A., \& Massardo, A. (2003). Micro Humid Air Cycle: Part B-Thermoeconomic Analysis.

[36] Nishida, K., Takagi, T., \& Kinoshita, S. (2005). Regenerative steam-injection gas-turbine systems. Applied Energy, 81(3), 231-246.

[37] De Paepe, W., Contino, F., Delattin, F., Bram, S., \& De Ruyck, J. (2014). New concept of spray saturation tower for micro Humid Air Turbine applications. Applied Energy.

[38] De Paepe, W., Carrero, M. M., Bram, S., \& Contino, F. (2014). T100 Micro Gas Turbine Converted to Full Humid Air Operation: Test Rig Evaluation. Paper presented at the ASME Turbo Expo 2014: Turbine Technical Conference and Exposition.

[39] http://www.pact.ac.uk/.

[40] Turbec, A. B. (2000). Technical description-T100 microturbine system (Vol. Ver 3.0): Turbec Company. Italy. Turbec AB.

[41] Gas turbines - Procurement - Part 2: Standard reference conditions and ratings. (1997). ISO 3977-2: Geneva, Switzerland: International Organization for Standardization.

[42] Lee, J. J., Jeon, M. S., \& Kim, T. S. (2010). The influence of water and steam injection on the performance of a recuperated cycle microturbine for combined heat and power application. Applied energy, 87(4), 1307-1316. 